Archived version from NCDOCKS Institutional Repository http://libres.uncg.edu/ir/asu/

\title{
Appalachl̈ăn
}

B O O NE, NORTH CAROLINA

\section{The Relationship Between Undergraduate Attendance And Performance Revisited: Alignment Of Student And Instructor Goals}

\author{
By: James W. Westerman, Luis A. Perez-Batres, Betty S. Coffey, and Richard W. Pouder
}

\begin{abstract}
We revisit the relationship between attendance and performance in the undergraduate university setting and apply agency theory in the instructor-student context. Building on agency theory propositions in the educational setting advanced by Smith, Zsidisin, and Adams (2005), we propose that the student and instructor must align goals to promote the student's achievement of performance learning outcomes, and attendance functions as a behaviorbased alignment mechanism to encourage the convergence of faculty and student interests. Further, we propose that attendance does not equally affect lower- and higher-performing students and that absences are also negatively related to students' cumulative grade point average. We test these hypotheses with data from undergraduates enrolled in management courses at a state university in the southeast. Our results show that attendance is positively related to exam performance, there are more pronounced negative effects of an absence for lower-performing students than for higher performers, and absences are negatively related to a student's cumulative grade point average. We discuss the implications of our findings for students, instructors, and universities as well as practice in teaching and learning.
\end{abstract}

Westerman, J. W., Perez-Batres, L. A., Coffey, B. S. and Pouder, R. W. (2011), The Relationship Between Undergraduate Attendance and Performance Revisited: Alignment of Student and Instructor Goals. Decision Sciences Journal of Innovative Education, 9: 49-67. doi:10.1111/j.1540-4609.2010.00294.x. Publisher version of record available at: https://onlinelibrary.wiley.com/doi/10.1111/j.1540-4609.2010.00294.x 


\title{
The Relationship Between Undergraduate Attendance and Performance Revisited: Alignment of Student and Instructor Goals
}

\author{
James W. Westerman ${ }^{\dagger}$ \\ Walker College of Business, Appalachian State University, ASU Box 32089, Boone, NC \\ 28608-2089, e-mail: westermanjw@appstate.edu \\ Luis A. Perez-Batres \\ Central Michigan University, Department of Management, College of Business Administration, \\ 204D Smith Hall, Mount Pleasant, MI 48859, e-mail: perez1la@ cmich.edu
}

Betty S. Coffey

Walker College of Business, Appalachian State University, ASU Box 32089, Boone, NC 28608-2089, e-mail: coffeybs@appstate.edu

Richard W. Pouder

Appalachian State University, Walker College of Business, ASU Box 32089, Boone, NC 28608-2089,e-mail: pouderrw@appstate.edu

\begin{abstract}
We revisit the relationship between attendance and performance in the undergraduate university setting and apply agency theory in the instructor-student context. Building on agency theory propositions in the educational setting advanced by Smith, Zsidisin, and Adams (2005), we propose that the student and instructor must align goals to promote the student's achievement of performance learning outcomes, and attendance functions as a behavior-based alignment mechanism to encourage the convergence of faculty and student interests. Further, we propose that attendance does not equally affect lowerand higher-performing students and that absences are also negatively related to students' cumulative grade point average. We test these hypotheses with data from undergraduates enrolled in management courses at a state university in the southeast. Our results show that attendance is positively related to exam performance, there are more pronounced negative effects of an absence for lower-performing students than for higher performers, and absences are negatively related to a student's cumulative grade point average. We discuss the implications of our findings for students, instructors, and universities as well as practice in teaching and learning.
\end{abstract}

Subject Areas: Agency Theory, Attendance, Business Education, and Student Performance.

${ }^{\dagger}$ Corresponding author. 


\section{INTRODUCTION}

An oft-heard Woody Allen quote is that "At least half of life is just showing up." Many college professors seem to share this opinion and express concern, even dismay, when their undergraduate students miss class (Chan, Shum, \& Wright, 1997). Because attendance has been shown to be an important factor in academic success, the relationship between attendance and academic performance continues to be studied (Gump, 2005). The assumption is that undergraduate students will perform best if they are present for participation and engagement in the learning experience offered in the class setting (Stanca, 2006).

However, empirical research has yet to address whether the attendanceperformance relationship affects all students in the same manner. In other words, does attendance equally affect high and low performers? An improved understanding of the attendance-performance relationship for specific learners might assist educators in developing better mechanisms to encourage students to demonstrate behaviors that will help them avoid the cycle of poor attendance, low performance, and diminished grade point averages (GPAs).

Our study explores the relationship between attendance and performance in the business management higher education classroom and tests whether this relationship is consistent for both high and low performers. As a conceptual lens, we apply agency theory as interpreted by Smith, Zsidisin, and Adams (2005) for the instructor-student context. Within this setting, we build and test hypotheses on the relationship between attendance and performance. We propose that student attendance is one mechanism that helps to align the goals of the instructor and the student in the university undergraduate setting. Specifically, we examine the attendance-performance relationship for high and low performers. After reporting our results, we discuss the implications of our findings for the student, instructor, and university, as well as the limitations of our study and suggestions for future research.

\section{AGENCY THEORY RELATIONSHIP IN THE CLASS SETTING}

University instructors have an obligation for ensuring that students are prepared for societal roles, including acquiring the knowledge and ability to act wisely on that knowledge within society (Colby, Ehrlich, Beaumont, \& Stephens, 2003). In higher education settings, students' performance in their classes (primarily in the form of grades) represents a primary indicator used to communicate the preparedness of university students. Instructor evaluation of student performance in a course serves as the basis for the assignment of grades. One challenge that university instructors face is in determining the most effective and efficient mechanisms to engage students in the assurance of learning in the class setting. Research by Smith et al. (2005) is particularly informative in this regard. They developed a theoretical framework using agency theory to explain student evaluation mechanisms, which help us understand some of the factors that influence the alignment of goals in the student-instructor relationship. In this paper, we apply and extend work by Smith et al. (2005) in proposing that attendance is a mechanism that helps to align the 
relationship between the university instructor and undergraduate student toward achieving desired learning outcomes.

Agency theory describes the relationship between two or more parties in which one party (the principal) engages the other party (the agent) to perform some activity on behalf of the principal (Berle \& Means, 1932; Jensen \& Meckling, 1976; Moe, 1984; Ross, 1973). Studies in agency theory have traditionally focused on issues regarding the separation of ownership and control in a business context, with special emphasis on the attendant costs associated with ensuring that managers as agents perform the tasks required by the shareholder-owners as principals. Given the appeal of its economics-based interpretation of principal-agent relationships, Eisenhardt (1989) recommended that agency theory be expanded to examine a "richer and more complex range of contexts" (p. 71). In line with this guidance, agency theory has been utilized as a theoretical and empirical framework for many different disciplines, including education (e.g., Kivisto, 2008).

Eisenhardt's (1989) seminal work on opportunities for expanding the use of agency theory also suggests that researchers explore microlevel dyad phenomena. Smith et al. (2005) followed this suggestion by examining the microlevel dyad of an instructor-student relationship. They draw from a central tenet of agency theory, which proposes that a principal delegates tasks to an agent and then takes steps to ensure that the outcome of an agent's efforts fulfill the principal's objectives. Accordingly, in summarizing work by Eisenhardt (1989) and Logan (2000), Smith et al. (2005) write that:

\begin{abstract}
"Agency theory is an appropriate theoretical framework for studying issues when one party, the principal, delegates and assesses the work of another party, the agent... In the instructor-student relationship, instructors can be seen as principals who delegate and assess work to students, who are the agents. The instructor's aim is to produce educated students and the student-as-agent is charged with the responsibility for fulfilling that goal. If instructors fail to accomplish this objective, the reputation of their programs and their ability to function as instructors suffers" (p. 32)
\end{abstract}

The instructor-student relationship must possess three elements to be appropriate for agency theory analysis. First, the principal must delegate tasks to the agent (instructors delegate knowledge acquisition of subject matter to students). Second, the principal must allocate resources to the agent for accomplishing the task (instructor-provided resources to aid in student knowledge acquisition include required readings, lectures, and other teaching materials). Third, a principal should be interested in the accomplishment of the task (faculty's interest in accomplishment of student knowledge acquisition includes for purposes of improved faculty teaching evaluations, enhanced faculty and university reputation, better job placement of graduates and student success in the workforce).

Smith et al. (2005) also consider the goal conflict and informational asymmetries inherent in an agency relationship:

“... research supports the common knowledge notion that learning can only take place with a willing participant (Burke \& Moore, 2003; Kinman \& Kinman, 2001; Kruck \& Lending, 2003; Zemke \& Zemke, 1988), thus placing responsibility for performance squarely on the student. This lends support 
to the approach advocated by the current article... that it is the student who

ultimately decides whether or not to yield the final product" (p. 32).

Academic work is inherently prone to informational asymmetries, as the agent (student) possesses more information about his or her own actions, abilities, and preferences in regard to completing a task than does the principal (faculty member). Further, once principals delegate decision-making to agents, they often have problems controlling them as agents' goals often differ from their own. Goal conflict can exist as students focus on the outcome or grades rather than knowledge acquisition.

Thus, in the context of agency theory, the alignment of the principal-agent (instructor-student) relationship is imperative to ensure achievement of desired learning outcomes. Various behavior-based mechanisms, such as student attendance, may help to ensure the alignment of interests of the parties-instructor and undergraduate student-in achieving the learning outcomes.

\section{LEARNING OUTCOMES AND BEHAVIOR-BASED ALIGNMENT MECHANISMS}

Outcome- and behavior-based indicators are central in explaining agency relationships (Eisenhardt, 1989) and thus help us to understand the alignment of interests in the instructor-student relationship (Smith et al., 2005). Outcome-based measures emphasize results (Choi \& Liker, 1995) and represent learning of class content demonstrated in the form of multiple-choice and true-false exams, essays, case analyses, and other student products as the basis of the course grade (Smith et al., 2005). Behavior-based measures focus on processes (Eisenhardt, 1989), tasks, and activities of the student including class attendance, participation, utilization of office hours, and number of computer hours logged (Smith et al., 2005). Smith et al. (2005) suggest that the behavior-based process measures are indicators that allow instructors to observe, detect, and correct patterns of individual student behavior that may lead to their reduced performance.

Building on agency theory tenets, Smith et al. (2005) developed a number of propositions to explain behavior-based measures related to the studentinstructor relationship at the undergraduate and graduate level. For example, research-oriented faculty may focus on more strategically important graduate students (enhanced principal-agent risk when teaching undergraduates), as they might experience less alignment of goals with undergraduate students than with graduate students (greater goal conflict). Undergraduates may also be subject to less outcome uncertainty including insignificant research results for theses (less environmental uncertainty). Larger undergraduate class size and the nature of the undergraduate content may lead to higher levels of programmability and efficiency (enhanced task programmability). The agency theory propositions advanced by Smith et al. (2005) suggest that instructors will disproportionately utilize outcome-based evaluation measures in classes with students deemed as less strategically important by instructors and higher education institutions. In other words, behavior-based evaluation requires the commitment of "extensive instructional resources" on the part of faculty to effectively observe and provide feedback on student learning 
processes associated with poor student performance (Smith et al., 2005, p. 35). The concern is that undergraduate education will suffer if process-based evaluation measures emphasizing and providing for the interactions and feedback between students and faculty to align their interests become increasingly absent. Our current study draws on agency theory to investigate the relationship of attendance (behavior-based) and performance (outcome-based) in the undergraduate business management classroom.

\section{ATTENDANCE-PERFORMANCE RELATIONSHIP}

We suggest, in an agency theory context, attendance represents a particularly efficient and effective behavioral measure functioning as an alignment mechanism to measure and promote behaviors that affect performance. In terms of goal asymmetry, in our experience as faculty members, it is common for undergraduate students to ask whether a specific topic will appear on the test. The assumption is that students study (learn) only what is most efficient for attaining a given grade. Further, taking attendance is not a particularly onerous or time-consuming process (particularly if using sign-in sheets, student identification scanners, seating charts, or student name placards). As a result, its innate efficiency should significantly reduce the arguments against its use in the undergraduate classroom regardless of the type of institution or pressures on an instructor. Moreover, the importance of attendance as an assessment device may be increasing. As students have the freedom to attend classes, the issue is one of time allocation as students choose among academic and nonacademic activities (Marburger, 2006). This freedom might contribute to an absenteeism problem, albeit not a small one. For example, Romer (1993) found that about a third of students in an economics class were absent during any given class meeting, and Marburger (2001) found absenteeism (or shirking behavior) (Gomez-Mejia \& Balkin, 1992) to be higher on Fridays and higher as the semester progressed. At least for some university undergraduate students, regular class attendance may be one way to align student interests with those of the instructor to achieve the desired learning outcomes. Although taking attendance is a relatively efficient process, the open question is whether attendance is "effective" in enhancing student performance in the business management classroom.

Previous research has shown a positive relationship between attendance and student class performance (from here on performance) in business courses. Empirical studies in business disciplines representing the "hard skill" (Elmuti, 2004; Taylor, 2005) fields of accounting, economics, and finance (Chan, Shum, \& Wright, 1997; Cohn \& Johnson, 2006; Devadoss \& Foltz, 1996; Didia \& Hasnat, 1998; Douglas \& Sulock, 1995; Durden \& Ellis, 1995; Launius, 1997; Lumsden \& Scott, 1987; Marburger, 2001; Park \& Kerr, 1990; Romer, 1993; Schmidt, 1983; Stanca, 2006) have demonstrated a positive relationship between attendance and performance. Empirical support also exists in other fields of study including physics (Sharma, Mendez, \& O'Byrne, 2005), dental medicine (Newman, Schuman, Fields, \& Nunez, 1981), health science (Jenne, 1973), psychology (Gunn, 1993; Jones, 1984), sociology (Day, 1994), statistics (Rodgers, 2001), and elementary education (Lamdin, 1996). While these descriptive studies demonstrate a positive relationship, the studies give little attention to a theoretical explanation for the 
relationship. We are interested in examining the attendance-performance relationship in the management discipline to determine if results are consistent with previous findings in other disciplines. Currently, there is no empirical study demonstrating a relationship in the management higher education context. As such, this study contributes to the literature through examination of the attendance-performance relationship in the management discipline, while also providing an extension of existing research through offering a theoretical foundation in agency theory.

As noted through agency theory arguments, the use of behavior-based measures such as attendance may increase the ability of faculty to engage students who are present in the learning process and transfer of knowledge among participants and allow students to demonstrate their knowledge through performance-based outcomes (grade in the course) (Smith et al., 2005). With regard to attendance and performance in the management classroom, we propose the following hypothesis:

Hypothesis 1: For a given testing period, student class absences will be negatively related to exam performance.

In the general context of agency theory, the moral hazard refers to the agent not putting in the "agreed-upon effort" (Eisenhardt, 1989, p. 61) as specified in the metaphor of a contract. In the context of the undergraduate classroom, the moral hazard occurs when students (agents) do not fulfill the expectations of the syllabus (contract). The lack of specification of attendance responsibilities (task programmability) may contribute to moral hazard by reducing the quality and quantity of faculty-student communication, cultivating misunderstanding between principals and agents. Lower-performing students may represent a potentially potent form of moral hazard, and instructors also have a stake in student outcomes (e.g., in the form of students not mastering the material adequately and in potentially lower student teaching evaluations for faculty). As a result, behavior-based measures may be particularly important for the alignment of goals involving lowerperforming undergraduate students.

Previous studies on attendance have not investigated whether attendance has different effects on different student groups. For example, do higher test performers benefit as much as lower test performers from more frequent attendance in class? Consistent with these explanations, attendance as a goal alignment mechanism for faculty and student interests should have a more positive effect for low performers, as the interests of low performers are further apart from those of the instructor. In other words, for low performers each absence greatly increases the interest divergence with that of the instructor. Thus, each absence results in a lower level of opportunity for learning engagement and transfer, hence reflected in the grade for the course. In contrast, attendance as an alignment mechanism for faculty and undergraduate student interests should have less positive effects for high performers whose interests align more closely with those of the instructor. In other words, for high performers, each absence should not necessarily increase the interest divergence with that of the instructor. Thus, each absence does not necessarily affect performance as measured by the grade in the course. Consistent with these arguments, we hypothesize the following: 
Hypothesis 2a: For a given testing period, the lower the student's cumulative grade point average, the higher the negative relationship between test performance and absenteeism.

Hypothesis 2b: For a given testing period, the higher the student's cumulative grade point average, the lower the negative relationship between test performance and absenteeism.

As the more successful students learn from their experience in courses (and fulfilling contracts) in higher education, we anticipate the development of a greater alignment of the student's (agent) preferences with those of the faculty (principal). As appropriate student behavior is repeatedly reinforced through outcomes (grades), the more highly performing student learns to become a cooperating party. As Eisenhardt (1989) notes, "If there is no goal conflict, the agent will behave as the principal would like, regardless of whether his or her behavior is monitored" (p. 62). Thus, we suggest that a form of cumulative reduced moral hazard may exist with more successful undergraduate students prior to their entering the class. To this end, we propose an inverse relationship between the number of student absences in a given class and the student's cumulative grade point average.

Hypothesis 3: Student absences in a class will be negatively related to a student's cumulative grade point average.

Based on the agency theory perspective, the goals of the instructor (principal) and the student (agent) should align to achieve the desired performance outcomes. To better understand the factors that will help to align the interests of the instructor and student in this relationship, we examine the relationship between attendance and performance in business higher education and test whether this relationship is consistent for both high and low performers.

\section{METHODS}

\section{Sample}

Our subjects were 426 undergraduate business students enrolled in management courses taught by four instructors at the Association to Advance Collegiate Schools of Business accredited comprehensive university in the southeastern United States. To achieve a broad representation of management courses, four of the core fields in the discipline-human resource management, organizational behavior, social responsibility, and strategic management-were represented in the study. Three of the courses were required for all business majors (strategic management, organizational behavior, and social responsibility), and human resource management was an elective.

Subjects were enrolled in a traditional semester length course, had been admitted to the college of business, held the academic classification of junior or senior status, and were less than 25 years old. Students enrolled in the courses represented a typical range of business majors including accounting, economics, finance, management, marketing, and computer information systems. The enrollment averaged 21 students in each management class. 


\section{Dependent Variables}

\section{Performance}

Student performance, a proxy for learning transfer in a given time period, is the primary dependent variable. It was measured using the student's score on an examination given at the same interval in each course during the semester. The examination in each management course was written to test the student's knowledge of material covered in that course, during a particular period. Questions were related to the reading assignments and class discussion of the topics. The exam in each course consisted of a combination of short essay and multiple choice questions. Unlike final grades in the course, the examination scores do not have an attendance component. The measurement for the variable is the natural logarithm of the test grade earned by each student represented in the sample. To further analyze the stability of the relationship between attendance and performance, we subcategorized the performance variable to determine whether performance fell in a specific benchmark as follows:

\section{Perf25 (25th percentile)}

The dummy variable indicates whether student performance $(\log )$ fell just above the bottom quartile of all the tests takers in the sample.

\section{Perf50 (50th percentile)}

The dummy variable indicates whether student performance (log) fell within the top $50 \%$ of all the tests takers in the sample.

\section{Perf75 (75th percentile)}

The dummy variable indicates whether student performance (log) fell within the top quartile (highest $25 \%$ ) of all the tests takers in the sample.

\section{Independent Variables}

\section{Number of absences}

Each instructor recorded the daily absence of students enrolled in the course. At the beginning of the semester, students were informed that attendance would be taken at each scheduled class meeting, and that it would represent a portion of their final grade in the course. Each class met twice a week for 75 minutes. The variable represents the total number of absences for each student in the sample before each test.

\section{Control Variables}

\section{Cumulative GPA}

The grade point average variable represents a proxy for prior academic success and is a general measure of student academic ability and achievement (Park \& Kerr, 1990). Several studies have found a positive relationship between cumulative GPA and test performance (Black \& Duhon, 2003). To control for this effect we include the student cumulative GPA. We obtained information on the cumulative GPA at the beginning of the semester from university records. GPA values could range from 0 to 4.0 . 


\section{Gender}

The empirical evidence on the influence of gender on student performance has been mixed. Bouillon and Doran (1992), Durden and Ellis (1995), Peiperl and Trevelyan (1997), Borde (1998), and Didia and Hasnat (1998) found no consistent gender differences in student performance. However, Cheung and Kan (2002), Krohn and O'Connor (2005), Lipe (1989), Launius (1997), and Anderson and Benjamin (1994) found a significant relationship between gender and student performance. Given the mixed results in previous studies, we controlled for gender (male $=1$ ).

\section{Course load}

We controlled for course load measured as the number of semester credit hours the student was enrolled in during the fall semester. In previous research, Didia and Hasnat (1998) found that semester course loads are positively correlated with student performance (i.e., the heavier a student's semester course load, the better the performance). Typically, an undergraduate student at the sampled institution takes from 15 to 18 hours a semester, and registration for less than 12 hours places an undergraduate student on part-time status.

\section{Instructor}

Students were enrolled in different management courses with four different instructors. The instructor was coded as a nominal variable to control for possible instructor differences.

\section{Accounting}

In previous business studies, the academic background or major of the student has been considered as a factor that might influence the relationship between attendance and performance in a course (e.g., Cheung \& Kan, 2002, Didia \& Hasnat, 1998). Accounting students at the sampled institution have an excellent certified public accounting exam pass rate; therefore, we controlled for the possibility of positive bias based on the general quality of the undergraduate accounting students who were enrolled in these management courses. These data were collected after course grades were completed. An ordinal variable controlled for the difference in academic major.

\section{RESULTS}

Means, standard deviations, and correlations among the study variables are presented in Table 1.

To examine the relationship between the independent variable (number of absences) and test performance, we used regression analysis, while controlling for student GPA, student major (accounting), instructor, student course load, and student gender. Supporting the effect of attendance on student performance (Hypothesis 1), the results in Table 2 indicate a strong negative statistical relationship between number of absences and student test performance; the $t$-value is $-3.89(p<.001)$. 


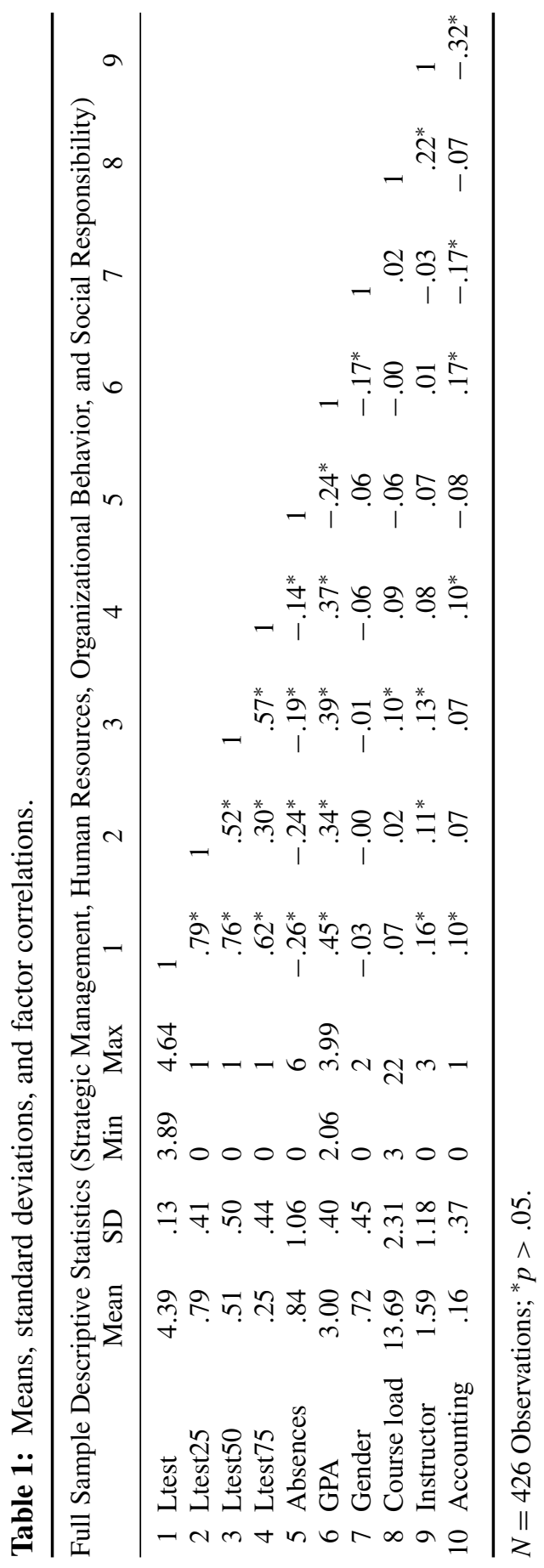


TABLE 2: Predictors of student performance.

\begin{tabular}{lccrr}
\hline Constructs & Coeff & S.E. & $t$ & $p>t$ \\
\hline Absences & $-.02^{* * *}$ & .01 & -3.89 & .000 \\
GPA & $.14^{* * *}$ & .01 & 9.11 & .000 \\
Control variables & & & & \\
$\quad$ Gender & .02 & .01 & 1.53 & .128 \\
$\quad$ Course load & .00 & .00 & .52 & .605 \\
$\quad$ Instructor & $.02^{* * *}$ & .01 & 4.26 & .000 \\
$\quad$ Accounting & $.03^{*}$ & .02 & 1.97 & .049 \\
$\quad$ Constant & $3.93^{* * *}$ & .06 & 67.25 & .000 \\
Regression statistics & & & & \\
$\quad$ Adj $R^{2}$ & .2539 & & & \\
$F$ & $25.11^{* * *}$ & & & \\
$N$ & 426 & & & \\
\hline
\end{tabular}

Dependent Variable: natural logarithm of student test grades.

${ }^{* * *} p<.001 ;{ }^{*} p<.05$.

To better understand the effect of attendance (number of absences) and performance, we conducted a series of logistic regression analyses in which the student performance variable (test scores) was categorized by benchmarks or quartiles at the 25th, 50th, and 75th percentile, Perf25, Perf50, and Perf75, respectively. Table 3 presents the results in the form of odds ratios, which measure how an independent (or control) variable affects the dependent variable in terms of likelihoods. The reported odds ratios for the absence variable are .66, .78, and .85 for Perf25, Perf50, and Perf75, respectively. This means that each absence taken by a student decreases his or her likelihood of performing at (or over) the 25th percentile (i.e., just above the bottom quartile) by $34 \%$ (i.e., $1-.66=34 \%$ ). For students at or above the 50th percentile, each absence decreases their likelihood of falling within this benchmark by $22 \%$. Lastly, for students performing within the top quartile (75th percentile), each absence would decrease their likelihood of falling within this benchmark by only $15 \%$. However, for students in this category (75th percentile), the absence variable is not statistically significant. These results suggest that absences affect students differently. In other words, lower test performers and average performers benefit the most from not missing class. In contrast, a lack of attendance was not significantly associated with test performance for the top quartile students. Results show that the negative effects of an absence were more pronounced for lower performers and less so (if at all) for higher performers. These results present strong support for Hypotheses $2 \mathrm{a}$ and $2 \mathrm{~b}$.

While this relationship has been tested in other disciplines, we also tested the relationship between number of absences in a class and a student's cumulative GPA to examine whether a form of cumulative reduced moral hazard may exist with more successful higher education business students prior to their entering the classroom. We found that a higher cumulative GPA is associated with a lower number of absences in a given class, providing support for Hypothesis 3 (see Table 4). These results (from Hypothesis 3) support findings from other higher education academic disciplines. 
Table 3: Logistic regression by quartile: predictors of student performance.

\begin{tabular}{|c|c|c|c|c|c|c|}
\hline Constructs & $\begin{array}{l}\text { Model } 1 \\
\text { Ltest25th }\end{array}$ & $z$ & $\begin{array}{l}\text { Odd Ratios } \\
\text { Model } 2 \\
\text { Ltest50th }\end{array}$ & $z$ & $\begin{array}{c}\text { Model } 3 \\
\text { Ltest75th }\end{array}$ & $z$ \\
\hline Abscences & $.66^{* * *}$ & -3.64 & $.78^{*}$ & -2.31 & .85 & -1.24 \\
\hline GPA & $12.21^{* * *}$ & 5.78 & $9.85^{* * *}$ & 7.04 & $9.26^{* * *}$ & 6.51 \\
\hline \multicolumn{7}{|c|}{ Control variables } \\
\hline Gender & 1.49 & 1.36 & 1.50 & 1.63 & 1.16 & .53 \\
\hline Course load & .99 & -.26 & 1.08 & 1.48 & 1.08 & 1.36 \\
\hline Instructor & $1.34^{* *}$ & 2.74 & $1.34^{* *}$ & 2.90 & 1.26 & 1.95 \\
\hline Accounting & 1.47 & .89 & 1.47 & 1.21 & $1.76^{\dagger}$ & 1.66 \\
\hline \multicolumn{7}{|c|}{ Regression statistics } \\
\hline $\mathrm{Chi}^{2}$ & $75.86^{* * *}$ & & $91.81^{* * *}$ & & $70.59^{* * *}$ & \\
\hline Pseudo $R^{2}$ & .1727 & & .1555 & & .1463 & \\
\hline$N$ & 426 & & 426 & & 426 & \\
\hline
\end{tabular}

Dependent variable:

Model $1=$ Ltest 25 th: test score fell above the bottom quartile of all the tests taken by the students in the sample.

Model $2=$ Ltest50th: test score fell within the top $50 \%$ of all the tests taken by the students in the sample.

Model 3 = Ltest75th: test score fell within the top quartile (highest 25\%) of all the tests taken by the students in the sample.

${ }^{* * *} p<0.001 ;{ }^{* *} p<0.01 ;{ }^{*} p<0.05 ;{ }^{\dagger} p<0.10$.

Table 4: Predictors of student attendance.

\begin{tabular}{lccrr}
\hline Constructs & Coeff & S.E. & \multicolumn{1}{c}{$t$} & $p>t$ \\
\hline GPA & $-.63^{* * *}$ & .13 & -4.88 & .000 \\
Control variables & & & & \\
$\quad$ Gender & .04 & .11 & .35 & .723 \\
$\quad$ Course Load & -.04 & .02 & -1.69 & .091 \\
$\quad$ Instructor & .07 & .05 & 1.62 & .106 \\
Accounting & -.06 & .15 & -.38 & .704 \\
$\quad$ Constant & $3.11^{* * *}$ & .50 & 6.17 & .000 \\
Regression statistics & & & & \\
Adj $R^{2}$ & .0591 & & & \\
$F$ & $6.34^{* * *}$ & & & \\
$N$ & 426 & & & \\
\hline
\end{tabular}

Dependent variable: Number of student absences per period (before a test).

${ }^{* * *} p<.001$.

\section{DISCUSSION}

The present study contributes to the existing literature on the relationship between student attendance and performance by (1) using an agency theory lens to examine the effectiveness of a behavioral measure in predicting student outcomes; (2) extending the research on the attendance-performance relationship to the 
management discipline; and (3) examining the differential effects of absenteeism on low- and high-performing students. Consistent with research in other disciplines, our results suggest an inverse relationship between absenteeism and performance in management courses. Adding to the findings from previous studies, our study introduces a theoretical explanation for the important relationship between attendance and performance. Most interestingly, our results suggest that these variables affect students differently. Specifically, our research indicates that the negative effects of absenteeism are more pronounced for low performers than for high performers. Absences seem to have no significant effect on the performance of top quartile students. Thus, regular class attendance has greater benefits for the students whose interests are less aligned with the instructor.

These results are consistent with the propositions suggested by Smith et al. (2005) in that behavior-based evaluation mechanisms, such as attendance, are effective in functioning to improve student performance. However, unlike many behavior-based measures, the use of attendance as a performance evaluation measure is not significantly labor intensive, and it may be one of the few behavior evaluation measures to combine effectiveness with efficiency. From an agency theory perspective, attendance can function as an information system for faculty revealing student (agent) behavior to faculty (the principal) and reducing agent opportunism. Further, attendance as a performance measure can assist in creating a more extensive student-instructor relationship with greater communication creating enhanced student-faculty goal alignment and reduced moral hazard. Moreover, taking attendance can provide for the early detection of problematic behaviors and deteriorating performance on the part of students to assist in timely interventions.

These findings suggest that devoting resources to improving attendance in the management and business higher education classroom is warranted. In the field of economics education, for example, Marburger (2006) found that a compulsory attendance policy significantly reduced absenteeism and improved student exam performance. At the secondary education level, research by Brokowski and Dempsey (1979) found a positive relationship between attendance and performance. Further, these authors suggest instructors reward for attendance on their syllabi and implement mandatory attendance policies, which may function to improve goal alignment and the saliency of the contract to the agent. In another study, Moore (2003) indicated the value of class attendance in nonmajor science classes and demonstrated that class attendance is influenced by whether students receive credit for attending class. Additional research within each discipline is needed to empirically understand the most effective and efficient methods for faculty to encourage student attendance in a manner that improves performance.

Results of this preliminary study may be particularly helpful to faculty in improving the performance of struggling undergraduate students. Our results indicate that poor attendance is directly related to reduced academic performance in lower quartile students. Implementation of attendance as a performance evaluation measure would be particularly effective in improving lower-performing student outcomes. Future research could examine the relationship between attendance and student performance in distance education courses to see if a similar 
pattern emerges. For example, the nonsignificant relationship between attendance and grades among top quartile students may indicate a differential propensity for their academic success in distance education. As higher educational institutions are becoming increasingly concerned about the content, format, delivery, and assessment of courses and provision of effective learning environments, further research in this area would be informative.

The results of this study may have implications for applied business practice. Our research suggests that only the top quartile students are successful at transcending the attendance-performance linkage. As many firms are moving to flexible scheduling and even "results only work environments" in which employees have complete self-determination over their own schedules (Conlin, 2006), our results imply that the top quartile employee performers are more likely to be trusted with a flexible scheduling system.

As this research consisted of an initial exploratory study, there exist limitations. A limitation that this study shares with similar research in other disciplines is that we collected data during one semester and at one higher educational institution. However, support for longitudinal stability has been demonstrated in the economics discipline, as research by Cohn and Johnson (2006) indicated a consistent attendance-performance relationship over a period of 5 years. Nonetheless, future research should benefit from the collection of cross-sectional and longitudinal data. Additional research should also examine the relative significance of the effect of student absence on performance in relation to other learning activities, processes, and assessments. There are a number of potential variables that may mediate or moderate any attendance-performance relationship, including faculty member skill levels in executing learning activities (including developing learning goals and the nature of the content and skills in the syllabus (Anderson, Krothwohl, \& Bloom, 2001; Huba \& Freed, 2000), the use of rubrics in assessment (Arter \& McTighe, 2001; Huba \& Freed, 2000; Stevens \& Levi, 2005), the diversity of learning styles in the classroom and faculty efforts to match them (Coffield, Moseley, Hall, \& Ecclestone, 2004a, 2004b; Hawk \& Shah, 2007), and the provision of timely and effective student feedback (Juwah et al., 2004; Michaelsen \& Schultheiss, 1988). Each represents areas ripe for future research in adding to our understanding of the attendance-performance relationship.

Although as business academics we frequently use students as subjects in testing theory in empirical research for organizations, we arguably do not focus enough on testing organizational theory in its effectiveness in managing our classrooms (justice perceptions, engagement, alignment of interest, etc.). As researchers, we focus on understanding the business world and contributing new knowledge to improve the success of organizations and their employees. However, we should also attempt to understand how to create and optimize performance in our own backyards, the classroom, as it is there that we are producing the human resources that will enhance the productivity of organizations across the globe. Business schools teach applied social science, and our graduates must develop a competitive skill set as a result of our instructional efforts. Our current students, as potential future managers, would be well served if we were to take a sharper focus on pedagogical research to improve student performance in the business education classroom. 
Ultimately, organizations rely on academic grades as one signal of the future performance of graduates in the workplace in their employee selection processes. If we intend for the higher education in business to have real world value for hiring managers, we need to more thoroughly understand the antecedents to student performance in our own classrooms, and ensure that the antecedents are among those that are effective in enhancing performance in the workplace. And if we are successful in understanding and communicating the influence of class attendance on academic performance to our students, perhaps they might be more inclined to take Woody Allen's advice and just show up.

\section{REFERENCES}

Anderson, G., \& Benjamin, D. (1994). The determinants of success in university introductory economics courses. Journal of Economic Education, 25(2), 99118.

Anderson, L. W., Krothwohl, D. R., \& Bloom, B. S. (2001). A taxonomy for learning, teaching, and assessing: A revision of bloom's taxonomy of educational objectives. New York: Longman.

Arter, J., \& McTighe, J. (2001). Scoring rubrics in the classroom. Thousand Oaks, CA: Corwin.

Berle, A. A., \& Means, G. C. (1932). The Modern corporation and private property. New York: Harcourt, Brace and World.

Black, H., \& Duhon, D. (2003). Evaluating and improving student achievement in business programs: The effective use of standardized assessment tests. Journal of Education for Business, 79, 90-98.

Borde, S. (1998). Predictors of student academic performance in the introductory marketing course. Journal of Education for Business, 73(5), 302-306.

Bouillon, M., \& Doran, B. (1992). The relative performance of female and male students in accounting principles classes. Journal of Education for Business, 67(4), 224-228.

Brokowski, W., \& Dempsey, R. (1979). Attendance policies and student performance. Clearing House, 53(3), 129-130.

Burke, L. A., \& Moore, J. E. (2003). A perennial dilemma in OB education: Engaging the traditional student. Academy of Management Learning \& Education, 2(1), 37-52.

Chan, K., Shum, C., \& Wright, D. (1997). Class attendance and student performance in principles of finance. Financial Practice and Education, 7(2), $58-65$.

Cheung, L., \& Kan, A. (2002). Evaluation of factors related to student performance in a distance-learning business communication course. Journal of Education for Business, 77(5), 257-263.

Choi, T., \& Liker, J. (1995). Bringing Japanese continuous improvement approaches to US manufacturing: The roles of process orientation and communications. Decision Sciences, 26, 589-620. 
Coffield, F. J., Moseley, D. V., Hall, E., \& Ecclestone, K. (2004a). Learning styles and pedagogy in post-16 learning: A systematic and critical review. London: Learning and Skills Research Centre.

Coffield, F. J., Moseley, D. V., Hall, E., \& Ecclestone, K. (2004b). Learning styles: What research has to say to practice. London: Learning and Skills Research Centre.

Cohn, E., \& Johnson, E. (2006) Class attendance and performance in principles of economics. Education Economics, 14(2), 211-233.

Colby, A., Ehrlich, T., Beaumont, E., \& Stephens, J. (2003). Educating citizens: Preparing America's undergraduates for lives of moral and civic responsibility. San Francisco: Jossey-Bass.

Conlin, M. (2006, December 11). Smashing the clock. Business Week.

Day, S. (1994). Learning in large sociology classes: Journals and attendance. Teaching Sociology, 22, 151-165.

Devadoss, S., \& Foltz, J. (1996). Evaluation of factors influencing student class attendance and performance. American Journal of Agricultural Economics, 78(3), 499-507.

Didia, D., \& Hasnat, B. (1998). The determinants of performance in the university introductory finance course. Financial Practice and Education, 8(1), 102107.

Douglas, S., \& Sulock, J. (1995). Estimating educational production functions with correction for drops. Journal of Economic Education, 26, 101-112.

Durden, G., \& Ellis, L. (1995). The effects of attendance on student learning in principles of economics. American Economic Review, 85(2), 343-346.

Eisenhardt, K. M. (1989). Agency theory: An assessment and review. Academy of Management Review, 14(1), 57-74.

Elmuti, D. (2004). Can management be taught? Management Decision, 42, 439453.

Gomez-Mejia, L. R., \& Balkin, D. B. (1992). Determinants of faculty pay: An agency theory perspective. Academy of Management Journal, 35(5), 921955.

Gump, S. E. (2005). The cost of cutting class: Attendance as a predictor of success. College Teaching, 53(1), 21-26.

Gunn, K. (1993). A correlation between attendance and grades in a first-year psychology class. Canadian Psychology, 34, 201-202.

Hawk, T. F., \& Shah, A. J. (2007). Using learning style instruments to enhance student learning. Decision Sciences Journal of Innovative Education, 5(1), $1-19$.

Huba, M. E., \& Freed, J. E. (2000). Learner-centered assessment on college campuses: Shifting the focus from teaching to learning. Boston: Allyn and Bacon.

Jenne, F. (1973). Attendance and student proficiency change in a health science class. Journal of School Health, 43, 125-126. 
Jensen, M. C., \& Meckling, W. H. (1976). Theory of the firm: Managerial behavior, agency costs and ownership structure. Journal of Financial Economics, 3(4), 305-360.

Jones, C. (1984). Interaction of absences and grades in a college course. The Journal of Psychology, 116, 133-136.

Juwah, C., Macfarlane-Dick, D., Matthew, B., Nicol, D., Ross, D., \& Smith, B. (2004). Enhancing student learning through effective formative feedback. York, UK: The Higher Education Academy Generic Centre.

Kinman, G., \& Kinman R. (2001). The role of motivation to learn in management education. Journal of Workplace Learning, 13(3/4), 132-143.

Kivisto, J. (2008). An assessment of agency theory as a framework for the government-university relationship. Journal of Higher Education Policy and Management, 30(4), 339-350.

Krohn, G., \& O'Connor, C. (2005). Student effort and performance over the semester. Research in Economic Education, 36(1), 3-29.

Kruck, S. E., \& Lending, D. (2003). Predicting academic performance in an introductory college-level IS course. Information Technology, Learning and Performance Journal, 21(2), 9-15.

Lamdin, D. (1996). Evidence of student attendance as an independent variable in education production functions. Journal of Educational Research, 89(3), $155-162$.

Launius, M. (1997). College student attendance: Attitudes and academic performance. College Student Journal, 31(1), 86-92.

Lipe, M. (1989). Further evidence on the performance of female versus male accounting students. Issues in Accounting Education, 4(1), 144-152.

Logan, M. S. (2000). Using agency theory to design successful outsourcing relationships. International Journal of Logistics Management, 11(2), 21-32.

Lumsden, K., \& Scott, A. (1987). The economics student reexamined: Male-female differences in comprehension. Journal of Economic Education, 18(3), 365375 .

Marburger, D. (2001). Absenteeism and undergraduate exam performance. Journal of Economic Education, 32(2), 99-109.

Marburger, D. (2006). Does mandatory attendance improve student performance? Journal of Economic Education, 37, 148-155.

Michaelsen, L. K., \& Schultheiss, E. E. (1988). Making feedback helpful. Organizational Behavior Teaching Review, 13(1), 109-113.

Moe, T. M. (1984). The new economics of organization. American Journal of Political Science, 28(4), 739-777.

Moore, R. (2003). Attendance and performance: How important is it for students to attend class? Journal of College Science Teaching, 32(6), 367-371.

Newman, S., Schuman, N., Fields, W., \& Nunez, L. (1981). Dental students' grades and their relationship to classroom attendance. Journal of Dental Education, 45(6), 360-361. 
Park, K., \& Kerr, P. (1990). Determinants of academic performance: A multinomial logit approach. Journal of Economic Education, 21(1), 101-111.

Peiperl, M., \& Trevelyan, R. (1997). Predictors of performance at business school and beyond: Demographic factors and the contrast between individual and group outcomes. Journal of Management Development, 15(5-6), 354367.

Rodgers, J. (2001). A panel-data study of the effect of student attendance on university performance. Australian Journal of Education, 45(3), 284295.

Romer, D. (1993). Do students go to class? Should they? Journal of Economic Perspectives, 7(3), 167-174.

Ross, S. A. (1973). The economic theory of agency: The principal's problem. American Economic Review, 63(2), 134-139.

Schmidt, R. (1983). Who maximizes what? A study in student time allocation. American Economic Review, 73, 23-28.

Sharma, M., Mendez, A., \& O’Byrne, J. (2005). The relationship between attendance in student-centered physics tutorials and performance in university examinations. International Journal of Science Education, 27(11), 13751389.

Smith, M. E., Zsidisin, G. A., \& Adams, L. L. (2005). An agency theory perspective on student performance evaluation. Decision Sciences Journal of Innovative Education, 3(1), 29-46.

Stanca, L. (2006). The effects of attendance on academic performance: Panel data evidence for introductory microeconomics. Journal of Economic Education, 37(3), 251-266.

Stevens, D. D., \& Levi, A. J. (2005). Introduction to rubrics. Sterling, VA: Stylus.

Taylor, A. (2005). What employers look for: The skills debate and the fit with youth perceptions. Journal of Education \& Work, 18(2), 201-218.

Zemke, R., \& Zemke, S. (1988). 30 things we know for sure about adult learning. Training, 25(7), 57-61.

James W. Westerman serves as the Duane D. Daggett Professor of Management at Appalachian State University in Boone, North Carolina. His recent research includes narcissism in higher education, person-organization fit, and cross-cultural ethics.

Luis A. Perez-Batres is an assistant professor in the Department of Management at Central Michigan University. His current research interests rest within the broad disciplines of international business and strategic management and consist of three primary foci: sustainable development, firm responses to radical changes (e.g., liability of foreignness/localness), and scholarship (e.g., student performance). His work appears (or is in press) at the Journal of Business Ethics, Journal of Cleaner Production, Journal of International Management, Multinational Business Review, and the AIB Insights. 
Betty S. Coffey is a professor of management at the Walker College of Business, Appalachian State University. She received her PhD from The University of Tennessee and was a Fulbright scholar in the People's Republic of China. Her research and teaching interests include strategic management, international business education in China, and management scholarship of teaching and learning.

Richard W. Pouder is a professor of management in the Department of Management, Appalachian State University, Boone, North Carolina. His teaching focuses primarily on strategic management at undergraduate and graduate levels. His research interests include competition and geographic clustering, organizational restructuring, and management of technology and innovation. 